\title{
Baseline of visceral fat area and decreased CrossMark body weight correlate with improved pulmonary function after Roux-en-Y Gastric Bypass in Chinese obese patients with BMI $28-35 \mathrm{~kg} / \mathrm{m}^{2}$ and Type 2 diabetes: a 6-month follow-up
}

\author{
Yinfang $\mathrm{Tu}^{1+}$, Haoyong $\mathrm{Yu}^{1+}$, Yuqian Bao ${ }^{1}$, Pin Zhang ${ }^{2}$, Jianzhong $\mathrm{Di}^{2}$, Xiaodong $\mathrm{Han}^{2}$ and Weiping Jia ${ }^{1 *}$
}

\begin{abstract}
Background: Associations between demographic data and pulmonary function have not been adequately examined in patients that underwent Roux-en-Y Gastric Bypass (RYGB). This study was designed to examine changes in body fat distribution and metabolic parameters after RYGB and whether these changes correlated with improved lung function.

Methods: A retrospective review of 32 ethnic Chinese with obesity with body mass index (BMI) $28-35 \mathrm{~kg} / \mathrm{m}^{2}$ and type 2 diabetes (T2DM) was conducted, focusing on metabolic outcomes and pulmonary function 6 months after RYGB.

Results: Forced expiratory volume during first second (FEV1), percentage of forced expiratory volume during first second (FEV1 [\%pred]), forced vital capacity (FVC), and percentage of forced vital capacity (FVC [\%pred]) all improved significantly after RYGB. These increases all were negatively correlated with decreases in body weight and visceral fat area (VFA). The improvements of FEV1, FEV1 [\%pred] and FVC were also negatively correlated with baseline of body weight and VFA. Furthermore, increases in FEV1 and FVC were independently associated with baseline of VFA ( $\beta=-0.003, P=0.000 ; \beta=-0.004, P=0.002$, respectively).
\end{abstract}

Conclusions: The baseline of VFA and weight loss induced by RYGB independently correlated with improved pulmonary function in Chinese patients.

Keywords: Body weight, Obesity, Abdominal, Visceral fat, Diabetes, Type 2, Pulmonary function test

\section{Background}

Obesity adversely affects pulmonary function, especially in those exhibiting the restrictive pattern of functional impairment [1-3]. Such impairment is found in patients with impaired glucose tolerance (IGT), diabetes, metabolic syndrome and cardiovascular disease [3-5]. However, previous work examining the association of pulmonary function with abdominal obesity defined by body weight, waist

\footnotetext{
* Correspondence: wpjia@sjtu.edu.cn

${ }^{\dagger}$ Equal contributors

'Department of Endocrinology and Metabolism, Shanghai Jiao Tong University Affiliated Sixth People's Hospital, Shanghai Diabetes Institute, Shanghai Clinical Center of Diabetes, Shanghai Key Laboratory of Diabetes Mellitus, Shanghai Key Clinical Center for Metabolic Disease, Yishan Road 600 , Shanghai, China

Full list of author information is available at the end of the article
}

circumference (WC), hip circumference, body mass index (BMI), waist-to-height or waist-to-hip ratio remains controversial [1, 6-9]. Studies using visceral fat area (VFA) to more accurately measure abdominal obesity in morbidly obese T2DM patients and examine the correlation with pulmonary function are lacking.

Roux-en-Y gastric bypass (RYGB) is currently performed in T2DM subjects with BMI over $35 \mathrm{~kg} / \mathrm{m}^{2}$, with evidence from the literature that RYGB may be appropriate for Chinese T2DM patients with BMI $25-35 \mathrm{~kg} / \mathrm{m}^{2}$ [10]. By criteria HbA1c $<6.5 \%$, the pencentage of patients with diabetes remission were 61 to $93 \%$ at 12 months after gastric bypass $[11,12]$. For example, in T2DM patients with BMI $<35 \mathrm{~kg} / \mathrm{m}^{2}$ who underwent RYGB, BMI decreased from $34.6 \pm 0.8 \mathrm{~kg} / \mathrm{m}^{2}$ to $25.8 \pm 2.5 \mathrm{~kg} / \mathrm{m}^{2}$ and HbA1c levels decreased from $8.2 \pm 2.0 \%$ to $6.1 \pm 2.7 \%$, 
1 year after RYGB [13]. Furthermore, the VFA: subcutaneous fat area (SFA), ratio fell substantially after surgical intervention in obese patients with T2DM, suggesting that weight loss after RYGB preferentially affects abdominal fat, particularly visceral fat [14]. Several studies have found that mortality during bariatric surgery is associated with respiratory complications $[15,16]$. Postoperative respiratory complications including tachypnea, arterial oxygen desaturation, atelectasis, pneumonia, hypoxemia, and hypercapnia have all been noted [6]. Importantly, several studies that included long-term follow-up have found that weight loss after bariatric surgery greatly improves pulmonary function by increasing the forced vital capacity $(\mathrm{FVC})[17,18]$ and the forced expiratory volume in $1 \mathrm{~s}$ (FEV1) [18]. However, it has been proposed that ethnic differences exist among patients and, to date, neither cross-sectional nor longitudinal associations between demographic data and pulmonary function have been adequately examined in Chinese patients treated with RYGB. Moreover, no study has yet used the reduction in VFA measured via magnetic resonance imaging (MRI), an accurate assessment of abdominal obesity, to study the association with improvements in pulmonary function after RYGB.

In this study, we evaluated baseline and changes in obesity by using body weight, BMI, VFA, SFA and in lipid metabolism. We then examined their association with improvement of pulmonary function in Chinese obese patients with BMI $28-35 \mathrm{~kg} / \mathrm{m}^{2}$ and T2DM, followed up to 6 months after RYGB.

\section{Methods}

\section{Patients}

This was a retrospective observational study approved by the Ethics Committee of the Shanghai Jiaotong Universtity affiliated No. 6 Hospital. Between February 2011 and January 2012, 32 Chinese patients (14 males and 18 females) aged 18 to 65 years, who were obese (BMI 28$35 \mathrm{~kg} / \mathrm{m}^{2}$ ) and who had T2DM, underwent laparoscopic RYGB (LRYGB) in our hospital and were enrolled in the present study. All patients underwent identical anaesthetic and surgical protocols. All surgeries were performed laparoscopically using a standardized technique. A $25 \mathrm{~mL}$ gastric pouch was divided from the distal remnant. The biliopancreatic and alimentary limbs were $100-120 \mathrm{~cm}$ in length. Pulmonary function (spirometry), weight, BMI, VFA, SFA and lipid metabolism were evaluated in the preoperative period and 6 months after surgery. Smoking history was recorded. Any patient with a history of open abdominal surgery, a serious disease (such as a heart or lung insufficiency) that was incompatible with surgery, an acute T2DM complication, severe alcohol or drug dependency, a mental disorder, type 1 $\mathrm{DM}$, secondary diabetes, an unstable psychiatric illness; who was a relatively high surgical risk (such as a patient with an active ulcer); or who was unable to adequately undergo pulmonary function testing was excluded. The written informed consent for participation in the study was obtained from participants.

\section{Pulmonary function tests}

Evaluation of pulmonary function was carried out with each patient in a sitting position, with nose clips in place, via body plethysmography (Jaeger Masterscreen Body, Würzburg, Germany). All tests were performed by the same team of technicians, who followed the recommendations of the American Thoracic Society (ATS)/ European Respiratory Society (ERS) [19]. Knudson's reference equations were used to derive predicted values of pulmonary function test results. Each patient repeated each test at least three times (yielding at least two reproducible and acceptable maneuvers). The FVC, FEV1, and FEV1/FVC ratio were measured. The results were considered to be reproducible if the second-highest FVC and FEV1 values were within $5 \%$ of the highest values. The highest measured FEV1 value and the corresponding FVC were coded to allow for computer analysis. The results were expressed in absolute values and as percentages of predicted normal values (FEV1 [\%pred] and FVC [\%pred]).

\section{Evaluation of VFA and SFA}

VFA and SFA were measured using a Philips Achieva 3.0-T MRI system (Philips Medical Systems, Eindhoven, the Netherlands) fitted with standard array coils; all subjects were in the supine position. Breath-hold FISP images centred on the L4-L5 intervertebral disc were obtained using standard localizer images. The following parameters were employed: Repetition Time $(\mathrm{TR})=4 \mathrm{~ms}$, Echo Time $(\mathrm{TE})=2 \mathrm{~ms}$, number of slices $=12$, slice thickness $=8 \mathrm{~mm}$, image matrix $256 \times 256$, and field-of-view $=500 \times 500 \mathrm{~mm}$. The four slices that were best-aligned with the L4-L5 disc were analyzed with the aid of the SliceOmatic 5.0 software package (Escape Medical Viewer V3.2) to obtain VFA and SFA values by fitting spline curves to points on the border of the subcutaneous and visceral regions. Non-fat areas within the visceral region were also outlined via spline fitting and subtracted from total visceral areas [20] .

\section{Statistical analysis}

All statistical analyses were performed using SPSS version 20.0 (SPSS, Chicago, IL). Data on normally distributed variables were expressed as means \pm standard deviations and analysed with the aid of the Shapiro-Wilk test. Data on skewed variables were expressed as medians (with interquartile ranges). After verifying the normality of distribution, the paired $t$-test was used to compare preoperative and 6-month postoperative results. Pearson correlation 
analysis was used to search for relationships among weight, BMI, VFA, SFA, measures of lipid metabolism, FEV1, FEV1 (\%pred), FVC, FVC (\%pred), and FEV1/FVC. Stepwise multiple regression analysis was used to identify independent parameters correlated with changes in pulmonary function. All reported $P$-values are two-tailed, and $P<0.05$ was considered to reflect statistical significance.

\section{Results}

Patient characteristics, including age, gender, smoking status, BMI, weight, VFA, SFA and lipid metabolism data, before and 6 months after RYGB, are shown in Table 1. The average reduction in VFA after RYGB was $70.9 \%$. This was much greater than the average drop in SFA (44.0\%). Significant reductions 6 months after surgery were noted in weight, BMI, and levels of total cholesterol (TC), triglycerides (TG) and low-density lipoprotein cholesterol (LDL-c). The BMI returned to normal in 21 patients and, in 8 , fell into the range of overweight $\left(25-28 \mathrm{~kg} / \mathrm{m}^{2}\right)$; only 3 patients remained obese $\left(\geq 28 \mathrm{~kg} / \mathrm{m}^{2}\right)$ despite significant reductions in their BMI.

FEV1, FEV1 (\%pred), FVC, and FVC (\%pred) increased significantly after surgery. Although the FEV1/FVC ratio did not change significantly, a tendency toward an increase was evident $(P<0.1)$ (Fig. 1).

Increases in FEV1, FEV1(\%pred), FVC and FVC(\%pred) were negatively correlated with baseline and decreases in weight and VFA. Although increase in FVC(\%pred) were not significantly correlated with baseline in weight and VFA, a possible correlation was evident $(P<0.1$; Table 2 and Fig. 2). Furthermore, significant negative correlations were evident between increases in FEV1(\%pred), FVC and FVC(\%pred) and decreases in BMI, and between increases in FVC(\%pred) and baseline of BMI. Increase in
FEV1 was positively correlated with increase in HDLc level. Significantly negative correlations were evident between increase in FEV1 (\%pred) and decrease in TG level. Changes in pulmonary function were not significantly correlated with baseline of lipid metabolism (Table 2).

Multiple stepwise regression analysis showed that increase in FEV1 (\%pred) $(\beta=-0.730, P<0.0001)$ and FVC (\%pred) ( $\beta=-0.747, P=0.001)$ were independently associated with decrease in weight, and that increases in FEV1 and FVC were independently associated with baseline of VFA $(\beta=-0.003, P=0.000 ; \beta=-0.004$, $P=0.002$, respectively), after adjustment for confounding factors. In addition, age was an independent risk factor for increase in FEV1 (\%pred), and increase of HDL-c was an independent risk factor for increase in FEV1 (Table 3).

\section{Discussion}

To the best of our knowledge, this is the first study to address the relationship between VFA and pulmonary function in obese T2DM Chinese patients. We observed that six months after RYGB surgery, significant reductions in BMI, body weight, VFA, SFA and TC, TG, LDLc were evident, and HDL-c levels were significantly higher. Lung function improved markedly, based on FEV1, FEV1 (\%pred), FVC, and FVC (\%pred) values. This is in keeping with previous work which found that FVC and the FEV1/FVC ratio recovered in morbidly obese females 6 months after surgery, and that FEV1 recovered by 1 year [21]. Though the improvement was not so evident, it had significance. Because respiratory failure(blood gas analysis suggests type I or type II respiratory failure) was a contraindication for surgery,

Table 1 Demographic data, VFA, SFA and lipid metabolism of obesity and T2DM before and 6 months after RYGB

\begin{tabular}{|c|c|c|c|c|}
\hline Variables & Before RYGB(V1) & After RYGB & $\Delta$ & P \\
\hline$n$ & 32 & - & - & - \\
\hline Male/Female & $14 / 18$ & - & - & - \\
\hline Age (years) & $45.09 \pm 11.26$ & - & - & - \\
\hline Smoker & 7 (21.9\%) & - & - & - \\
\hline Weight (kg) & $84.2 \pm 14.4$ & $66.8 \pm 11.0$ & $17.5 \pm 6.2$ & $<0.0001$ \\
\hline BMI $\left(\mathrm{kg} / \mathrm{m}^{2}\right)$ & $30.7 \pm 3.5$ & $24.4 \pm 2.4$ & $6.37 \pm 2.2$ & $<0.0001$ \\
\hline VFA $\left(\mathrm{cm}^{2}\right)$ & $123.5 \pm 36.4$ & $40.1 \pm 25.0$ & $87.6 \pm 36.3$ & $<0.0001$ \\
\hline $\mathrm{SFA}\left(\mathrm{cm}^{2}\right)$ & $278.9 \pm 82.7$ & $163.2 \pm 71.9$ & $122.8 \pm 59.9$ & $<0.0001$ \\
\hline TC (mmol/L) & $5.03 \pm 1.07$ & $4.27 \pm 1.16$ & $0.81 \pm 0.91$ & $<0.0001$ \\
\hline TG $(m m o l / L)$ & $1.69(1.37 \sim 2.80)$ & $0.98(0.84 \sim 1.50)$ & $0.74(0.48 \sim 1.14)$ & $<0.0001$ \\
\hline $\mathrm{HDL}-\mathrm{c}(\mathrm{mmol} / \mathrm{L})$ & $1.06 \pm 0.25$ & $1.17 \pm 0.23$ & $-0.14 \pm 0.19$ & $<0.0001$ \\
\hline LDL-c (mmol/L) & $2.86 \pm 0.85$ & $2.41 \pm 0.88$ & $0.55 \pm 0.86$ & $<0.0001$ \\
\hline
\end{tabular}

Data are mean \pm SD or median (interquartile range). BMI: Body mass index, VFA: visceral fat area, SFA: subcutaneous fat area, TC: total cholesterol; TG: triglyceride; HDL-c: high density lipoprotein cholesterol; LDL-c: low density lipoprotein cholesterol 


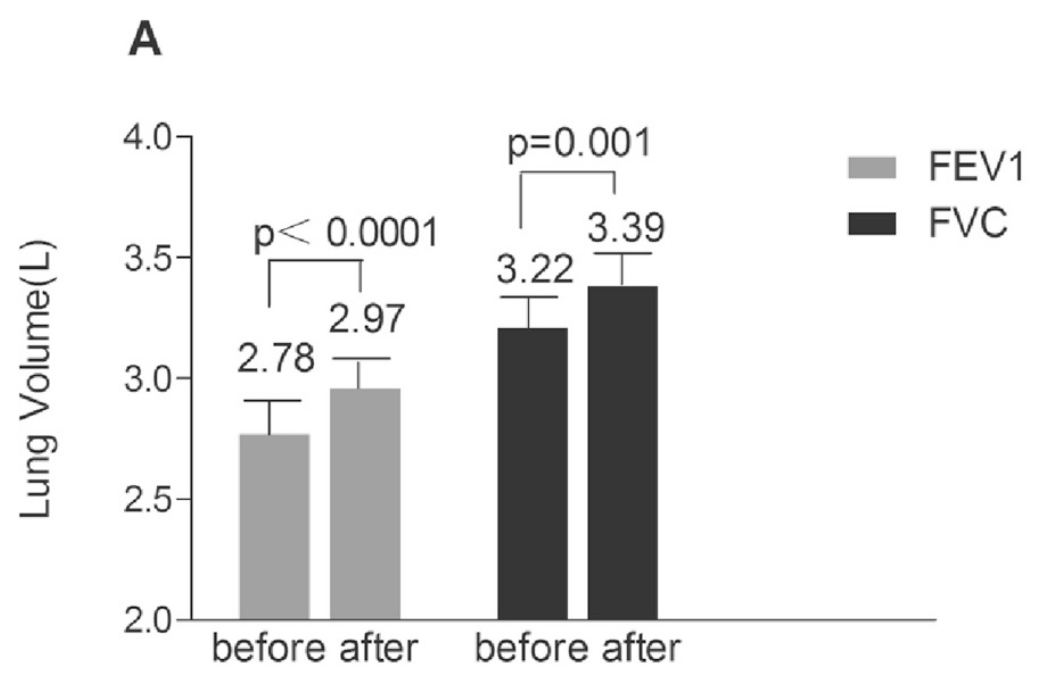

B

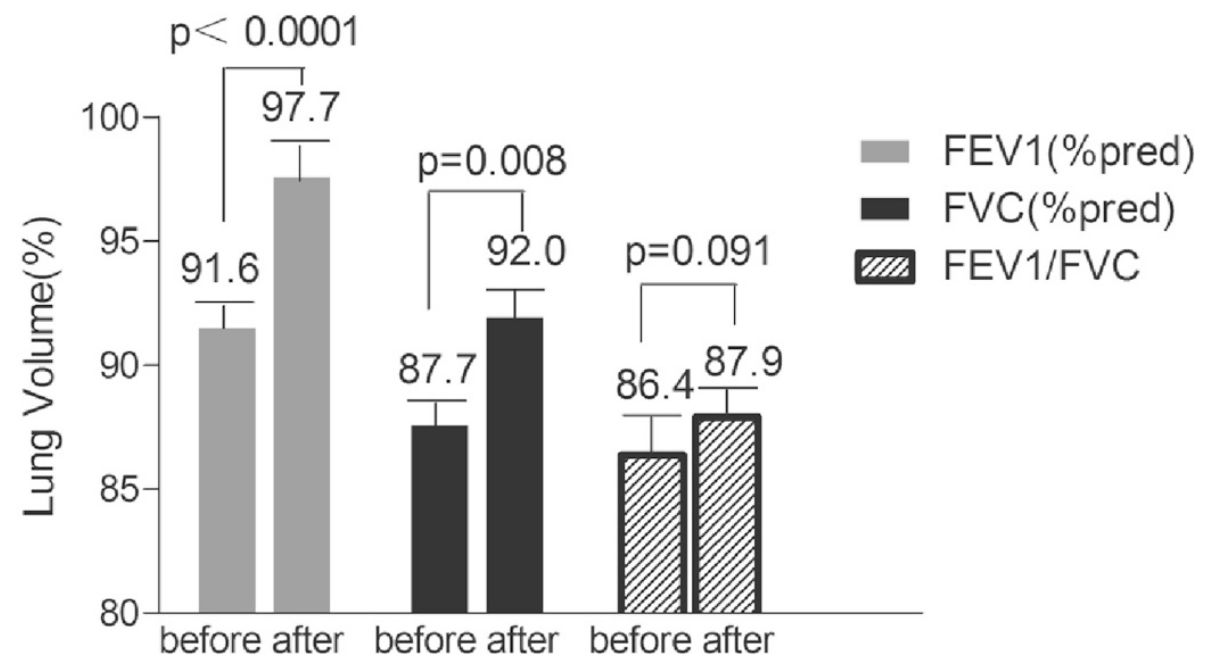

Fig. 1 Pulmonary results of obesity and type 2 diabetes before and 6 months after RYGB. FEV1:forced expiratory volume during first second. FEV1 (\%pred): percentage of forced expiratory volume during first second. FVC: forced vital capacity. FVC(\%pred): percentage of forced vital capacity. FEV1/FVC, \%: percentage of ratio of forced expiratory volume in $1 \mathrm{~s}$ to forced vital capacity. Increase in a FEV1 and FVC. b FEV1 (\%pred), FVC(\%pred) and FEV1/FVC. A paired $t$-test have been used here for statistical analysis

we enrolled patients with mild or moderate abnormal lung function, without apparent symptoms of dyspnea. We believed that studying a population with a higher BMI may suggest more benefit, especially if they were symptomatic. Considering the risks of anesthesia, we cannot yet enroll patients with apparent breathing difficulties.

Additional studies [6-8] have found that respiratory function improved with weight loss or waist-to-hip ratio, in morbidly obese patients 1 year after bariatric surgery. Paradoxically, waist-to-hip ratio did not significantly correlate with FVC and FEV1 after bariatric surgery in a Chinese population, although body weight,
BMI, WC, hip circumference, and waist-to-height ratio did correlate well with FVC and FEV1 [1]. One study has observed that respiratory drive was reduced after weight loss induced by bariatric surgery [9]. In the present study, 6 months after surgery, we observed increases in FEV1, FEV1 (\%pred) and FVC and clearly established that these were correlated with weight loss and baseline of weight. Others have reported similar results in populations varying in terms of ethnicity $[1,6-8]$.

Most importantly, we established for the first time that baseline and decreases in VFA was correlated with increases in FEV1, FEV1 (\%pred) and FVC. In particular, 
Table 2 Anthropometric and biochemical parameters showing significant correlations with changes in FEV1, FEV1(\%pred), FVC, FVC (\%pred)

\begin{tabular}{|c|c|c|c|c|c|c|c|c|}
\hline & $\Delta \mathrm{FEV} 1$ & & $\Delta$ FEV1 (\%pred) & & $\Delta \mathrm{FVC}$ & & $\triangle F V C$ (\%pred) & \\
\hline & Univariate $^{a}$ & & Univariate $^{a}$ & & Univariate $^{a}$ & & Univariate $^{a}$ & \\
\hline & $r$ & $P$ & $r$ & $P$ & $r$ & P & $r$ & $P$ \\
\hline$\Delta$ Weight (kg) & $-0.493^{* *}$ & 0.005 & $-0.620^{* *}$ & $<0.0001$ & $-0.522^{* *}$ & 0.003 & $-0.574^{* *}$ & 0.001 \\
\hline$\triangle \mathrm{BMI}\left(\mathrm{kg} / \mathrm{m}^{2}\right)$ & -0.354 & 0.051 & $-0.528^{* *}$ & 0.002 & $-0.440^{*}$ & 0.013 & $-0.533^{* *}$ & 0.002 \\
\hline$\triangle V F A\left(\mathrm{~cm}^{2}\right)$ & $-0.632^{* *}$ & $<0.0001$ & $-0.435^{*}$ & 0.015 & $-0.537^{* *}$ & 0.002 & -0.331 & 0.069 \\
\hline$\triangle S F A\left(\mathrm{~cm}^{2}\right)$ & -0.039 & 0.836 & -0.184 & 0.321 & -0.046 & 0.808 & -0.156 & 0.401 \\
\hline$\triangle \mathrm{TC}(\mathrm{mmol} / \mathrm{L})$ & 0.217 & 0.242 & 0.115 & 0.539 & 0.058 & 0.757 & -0.003 & 0.987 \\
\hline$\Delta \mathrm{TG}(\mathrm{mmol} / \mathrm{L})$ & -0.328 & 0.071 & -0.208 & 0.261 & $-0.364^{*}$ & 0.044 & -0.243 & 0.188 \\
\hline$\Delta \mathrm{HDL}-\mathrm{c}(\mathrm{mmol} / \mathrm{L})$ & $0.362^{*}$ & 0.045 & 0.116 & 0.535 & 0.069 & 0.711 & 0.123 & 0.510 \\
\hline$\Delta \mathrm{LDL}-\mathrm{c}(\mathrm{mmol} / \mathrm{L})$ & 0.306 & 0.094 & 0.165 & 0.374 & 0.236 & 0.202 & -0.120 & 0.513 \\
\hline Weight (kg) V1 & $-0.462^{* *}$ & 0.008 & $-0.398^{*}$ & 0.024 & $-0.381^{*}$ & 0.031 & -0.320 & 0.074 \\
\hline BMI $\left(\mathrm{kg} / \mathrm{m}^{2}\right) \mathrm{V} 1$ & -0.280 & 0.121 & -0.343 & 0.054 & -0.333 & 0.062 & $-0.370^{*}$ & 0.037 \\
\hline VFA $\left(\mathrm{cm}^{2}\right) \mathrm{V} 1$ & $-0.642^{* *}$ & 0.000 & $-0.439^{*}$ & 0.012 & $-0.534^{* *}$ & 0.002 & -0.336 & 0.060 \\
\hline $\mathrm{SFA}\left(\mathrm{cm}^{2}\right) \mathrm{V} 1$ & 0.041 & 0.823 & -0.029 & 0.876 & 0.021 & 0.909 & -0.051 & 0.781 \\
\hline $\mathrm{TC}(\mathrm{mmol} / \mathrm{L}) \mathrm{V} 1$ & 0.138 & 0.450 & 0.062 & 0.736 & 0.170 & 0.353 & 0.098 & 0.593 \\
\hline TG $(\mathrm{mmol} / \mathrm{L}) \mathrm{V} 1$ & -0.191 & 0.295 & -0.094 & 0.609 & -0.183 & 0.315 & -0.111 & 0.546 \\
\hline $\mathrm{HDL}-\mathrm{c}(\mathrm{mmol} / \mathrm{L}) \mathrm{V} 1$ & 0.342 & 0.055 & 0.096 & 0.601 & 0.278 & 0.124 & 0.067 & 0.717 \\
\hline LDL-c (mmol/L) V1 & 0.224 & 0.217 & 0.132 & 0.471 & 0.245 & 0.176 & 0.165 & 0.366 \\
\hline
\end{tabular}

aPearson's correlation analyses were performed

baseline of VFA was independently and significantly related to increases in FEV1 and FVC. A reduction in the VFA may have improved respiratory mechanics, consequently increasing FEV1, FEV1 (\%pred), and FVC, as shown by the significant correlations among these variables (Fig. 2). In several former studies, simple measurements of abdominal obesity such as WC, the waistto-hip ratio, or the waist-to-height ratio were found to be correlated with respiratory function [1, 6-8]. Furthermore, an increasing number of studies suggests that WC may be a better predictor of pulmonary functional impairment than other anthropometric obesity indices $[1,2,4]$. In the present study, the average reduction in VFA after RYGB far exceeded that of SFA, and was associated with improved respiratory function 6 months later. By accurately measuring the extent of visceral fat via MRI in the present study, we have clearly confirmed that obesity, especially abdominal obesity, affects pulmonary function. We believe that direct measurement of VFA using MRI affords a more accurate assessment of obesity than does WC or calculation of waist-to-hip ratios. We appreciate that MRI use is impractical in large-scale observational studies, however there is no doubt that it confers more accuracy and diagnostic power when applied to correlating obesity with related complications.
Obesity may influence pulmonary function because excess fat accumulation in the abdominal cavity and on the chest wall affects chest mechanics, increasing the work of breathing, reducing lung volumes, rendering respiratory muscles dysfunctional, impairing gas exchange and reducing exercise tolerance [7, 17, 22-26]. Our results may be attributable to upward physical pressure on the diaphragm caused by the increased abdominal volume of obese individuals. There has also been great interest in understanding the role of altered lipid metabolism in contributing to altered pulmonary function after weight loss. In keeping with a previous study, [27] we found no association between LDL-c levels and pulmonary function. Moreover, we found that only HDL-c levels were independently positively correlated with FEV1 and this may reflect the role played by HDL-c in immunoregulation and attenuation of inflammation [28].

The present study has several limitations, including a small sample size and a limited follow-up duration, however the current data and conclusions provide important verification on the predictive accuracy of VFA measures. Although the small number of patients imposed limitations on analyses, we regressed our data to explore whether immediate postoperative respiratory functions were associated with gender, age, BMI, lipid metabolism, weight or VFA. In general, weight and VFA, but not 

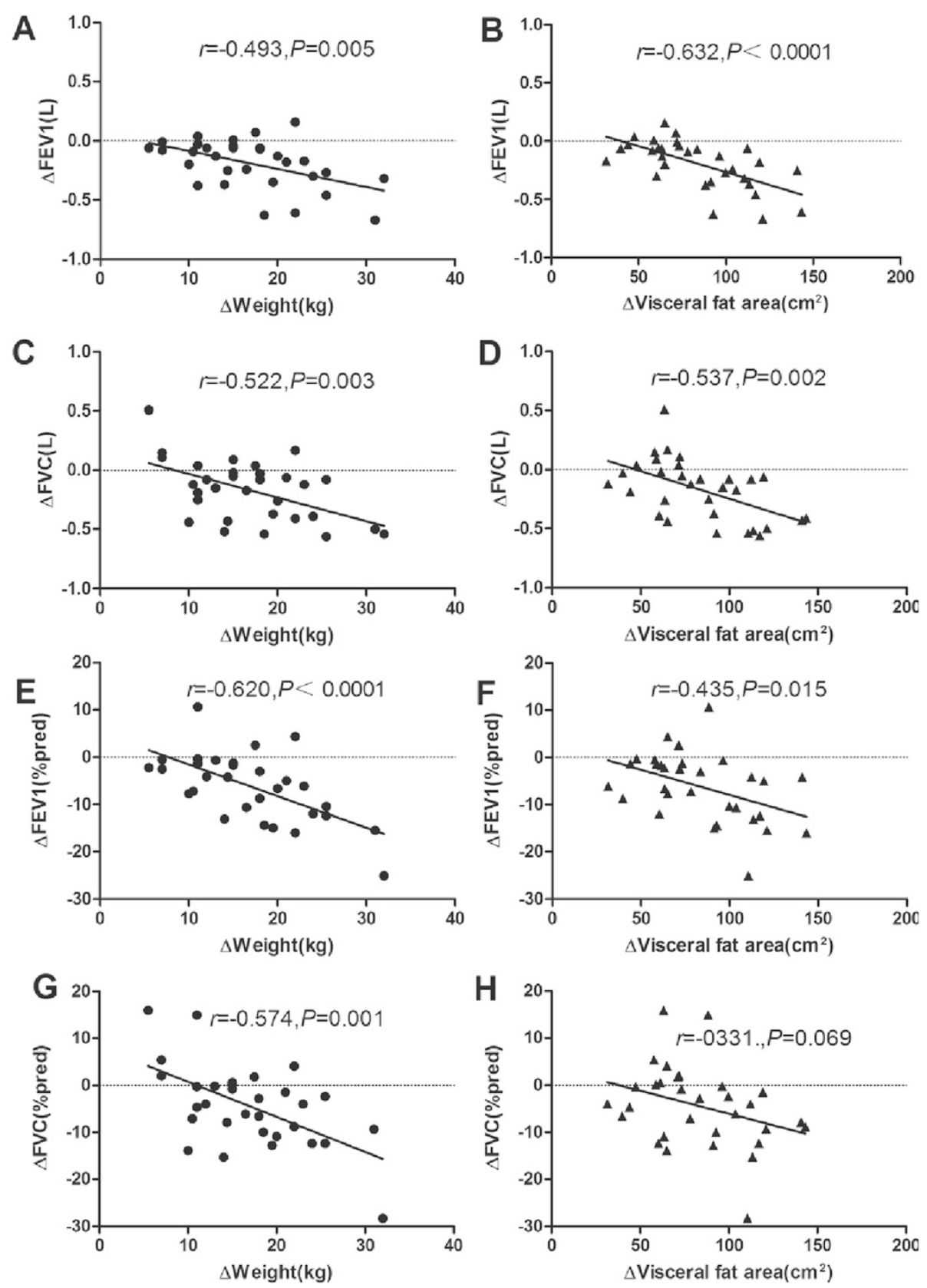

Fig. 2 Correlations between the changes in weight and VFA and changes in FEV1, FEV1(\%pred), FVC and FVC(\%pred). Correlation of changes in $\mathbf{a}$ weight and FEV1. $\mathbf{b}$ VFA and FEV1. $\mathbf{c}$ weight and FVC. $\mathbf{d}$ VFA and FVC. e weight and FEV1 (\%pred). $\mathbf{f} V F A$ and FEV1 (\%pred). $\mathbf{g}$ weight and FVC(\%pred). $\mathbf{h}$ VFA and FVC(\%pred)

SFA, influenced the rate of postoperative respiratory improvement. Another limitation is the lack of the control arm and hence it is not clear whether the findings are due to surgery itself or just the weight loss.

\section{Conclusions}

We found that VFA decreased significantly 6 months after LRYGB. Decrease of VFA and weight loss after bariatric surgery were correlated to improved respiratory performance, as evidenced by the increases in lung volumes (FEV1, FEV1 [\%pred], FVC, and FVC [\%pred]) of obese Chinese patients with T2DM. The improvements in pulmonary function 6 months after LRYGB were independently associated with the extent of weight loss and, in particular, baseline of VFA. We propose that patients who have more visceral fat may obtain greater benefit from RYGB surgery than those with less visceral fat. However, further studies with higher sample size and 
Table 3 Multiple stepwise regression analysis showing variables independently associated with changes in FEV1, FEV1(\%pred), FVC and FVC(\%pred)

\begin{tabular}{|c|c|c|c|c|c|c|c|c|}
\hline & $\triangle \mathrm{FEV} 1$ & & $\triangle \mathrm{FEV} 1$ (\%pred) & & $\triangle F V C$ & & $\Delta \mathrm{FVC}(\%$ pred) & \\
\hline & Multivariate & & Multivariate & & Multivariate & & Multivariate & \\
\hline & $\beta$ & P & $\beta$ & P & $\beta$ & P & $\beta$ & P \\
\hline Age (y) & & & -0.223 & 0.016 & & & & \\
\hline$\Delta$ Weight (kg) & & & -0.730 & $<0.0001$ & & & -0.747 & 0.001 \\
\hline VFA (cm2)V1 & -0.003 & $<0.0001$ & & & -0.004 & 0.002 & & \\
\hline$\Delta \mathrm{HDL}-\mathrm{c}(\mathrm{mmol} / \mathrm{L})$ & 0.355 & 0.022 & & & & & & \\
\hline
\end{tabular}

A multiple stepwise regression analysis was performed. Age, gender, changes in weight, BMI, VFA, SFA, TC, TG, HDL-C and LDL-C, and baseline of weight, BMI, VFA and SFA were included in the original model

long-term follow-up are needed to more conclusively establish the link between VFA and pulmonary functional improvement.

\section{Abbreviations}

BMI: Body mass index; VFA: Visceral fat area; SFA: Subcutaneous fat area; TC: Total cholesterol; TG: Triglyceride; HDL-c: High density lipoprotein cholesterol; LDL-c: Low density lipoprotein cholesterol; FEV1: Forced expiratory volume during first second; FEV1(\%pred): Percentage of forced expiratory volume during first second; FVC: Forced vital capacity; FVC(\%pred): Percentage of forced vital capacity; FEV1/FVC: \%, percentage of ratio of forced expiratory volume in 1 second to forced vital capacity.

\section{Competing interests}

The author(s) declare that they have no competing interests.

\section{Authors' contributions}

Weiping JIA and Yuqian BAO contributed to the conception or design of the work; Weiping JIA contributed to final approval of the version to be published and agreement to be accountable for all aspects of the work in ensuring that questions related to the accuracy or integrity of any part of the work are appropriately investigated and resolved; Haoyong YU, Yinfang TU, Pin Zhang, Jianzhong DI and Xiaodong HAN contributed to the acquisition and analysis or interpretation of data for the work; Haoyong YU and Yinfang TU drafted the work or revised it critically for important intellectual content. All authors read and approved the final manuscript.

\section{Acknowledgments}

This study was supported by grants from Chinese Society of Endocrinology, Key Program of the Shanghai Municipality for Basic Research (11JC1409600), 973 program (2011CB504001), National Major Scientific and Technological Special Project for "Significant New Drugs Development" (2011ZX09307-001-02).

\section{Author details}

'Department of Endocrinology and Metabolism, Shanghai Jiao Tong University Affiliated Sixth People's Hospital, Shanghai Diabetes Institute, Shanghai Clinical Center of Diabetes, Shanghai Key Laboratory of Diabetes Mellitus, Shanghai Key Clinical Center for Metabolic Disease, Yishan Road 600 , Shanghai, China. ${ }^{2}$ Department of General surgery, Shanghai Jiao Tong University Affiliated Sixth People's Hospital, Yishan Road 600, Shanghai, China.

\section{Received: 29 December 2014 Accepted: 1 June 2015}

\section{Published online: 09 June 2015}

\section{References}

1. Wei YF, Wu HD, Chang CY, Huang CK, Tai CM, Hung CM, et al. The impact of various anthropometric measurements of obesity on pulmonary function in candidates for surgery. Obes Surg. 2010;20:589-94.

2. Chen Y, Rennie D, Cormier YF, Dosman J. Waist circumference is associated with pulmonary function in normal-weight, overweight, and obese subjects. Am J Clin Nutr. 2007:85:35-9.

3. Lin WY, Yao CA, Wang HC, Huang KC. Impaired lung function is associated with obesity and metabolic syndrome in adults. Obesity (Silver Spring). 2006;14:1654-61.
4. Leone N, Courbon D, Thomas F, Bean K, Jego B, Leynaert B, et al. Lung function impairment and metabolic syndrome: the critical role of abdominal obesity. Am J Respir Crit Care Med. 2009;179:509-16.

5. Hickson DA, Burchfiel CM, Liu J, Petrini MF, Harrison K, White WB, et al. Diabetes, impaired glucose tolerance, and metabolic biomarkers in individuals with normal glucose tolerance are inversely associated with lung function: the Jackson Heart Study. Lung. 2011;189:311-21.

6. Marti-Valeri C, Sabate A, Masdevall C, Dalmau A. Improvement of associated respiratory problems in morbidly obese patients after open Roux-en-Y gastric bypass. Obes Surg. 2007;17:1102-10.

7. Wei YF, Wu HD. Candidates for bariatric surgery: morbidly obese patients with pulmonary dysfunction. J Obes. 2012;2012:878371.

8. Barbalho-Moulim MC, Miguel GP, Forti EM, Campos FA, Peixoto-Souza FS, Costa D. Pulmonary Function after Weight Loss in Obese Women Undergoing Roux-en-Y Gastric Bypass: One-Year Followup. ISRN Obes. 2013;2013:796454.

9. El-Gamal H, Khayat A, Shikora S, Unterborn JN. Relationship of dyspnea to respiratory drive and pulmonary function tests in obese patients before and after weight loss. Chest. 2005;128:3870-4.

10. Huang CK, Shabbir A, Lo CH, Tai CM, Chen YS, Houng JY. Laparoscopic Roux-en-Y gastric bypass for the treatment of type II diabetes mellitus in Chinese patients with body mass index of 25-35. Obes Surg. 2011;21:1344-9.

11. Adams TD, Gress RE, Smith SC, Halverson RC, Simper SC, Rosamond WD, et al. Long-term mortality after gastric bypass surgery. N Engl J Med. 2007;357:753-61

12. Yip S, Plank LD, Murphy R. Gastric bypass and sleeve gastrectomy for type 2 diabetes: a systematic review and meta-analysis of outcomes. Obes Surg. 2013;23:1994-2003.

13. Serrot FJ, Dorman RB, Miller CJ, Slusarek B, Sampson B, Sick BT, et al. Comparative effectiveness of bariatric surgery and nonsurgical therapy in adults with type 2 diabetes mellitus and body mass index $<35 \mathrm{~kg} / \mathrm{m}^{2}$. Surgery. 2011;150:684-91.

14. Chaston TB, Dixon JB. Factors associated with percent change in visceral versus subcutaneous abdominal fat during weight loss: findings from a systematic review. Int J Obes (Lond). 2008;32:619-28.

15. Boone KA, Cullen JJ, Mason EE, Scott DH, Doherty C, Maher JW. Impact of Vertical Banded Gastroplasty on Respiratory Insufficiency of Severe Obesity. Obes Surg. 1996;6:454-8.

16. Livingston EH, Huerta S, Arthur D, Lee S, De Shields S, Heber D. Male gender is a predictor of morbidity and age a predictor of mortality for patients undergoing gastric bypass surgery. Ann Surg. 2002;236:576-82.

17. Koenig SM. Pulmonary complications of obesity. Am J Med Sci. 2001;321:249-79.

18. Zavorsky GS, Kim DJ, Sylvestre JL, Christou NV. Alveolar-membrane diffusing capacity improves in the morbidly obese after bariatric surgery. Obes Surg. 2008;18:256-63.

19. Miller MR, Hankinson J, Brusasco V, Burgos F, Casaburi R, Coates A, et al. Standardisation of spirometry. Eur Respir J. 2005;26:319-38.

20. Gu Y, Yu H, Li Y, Ma X, Lu J, Yu W, et al. Beneficial effects of an 8-week, very low carbohydrate diet intervention on obese subjects. Evid Based Complement Alternat Med. 2013;2013:760804.

21. de Souza SA, Faintuch J, Cecconello I. Spirometric function improves in the morbidly obese after 1-year post-surgery. Obes Surg. 2010;20:1273-7.

22. Sugerman HJ, Fairman RP, Sood RK, Engle K, Wolfe L, Kellum JM. Long-term effects of gastric surgery for treating respiratory insufficiency of obesity. Am J Clin Nutr. 1992;55:597S-601S. 
23. Santamaria F, Montella S, Greco L, Valerio G, Franzese A, Maniscalco M, et al. Obesity duration is associated to pulmonary function impairment in obese subjects. Obesity (Silver Spring). 2011;19:1623-8.

24. Lotti P, Gigliotti F, Tesi F, Stendardi L, Grazzini M, Duranti R, et al. Respiratory muscles and dyspnea in obese nonsmoking subjects. Lung. 2005;183:311-23.

25. Steele RM, Finucane FM, Griffin SJ, Wareham NJ, Ekelund U. Obesity is associated with altered lung function independently of physical activity and fitness. Obesity (Silver Spring). 2009;17:578-84.

26. Faintuch J, Souza SA, Valezi AC, Sant'Anna AF, Gama-Rodrigues JJ. Pulmonary function and aerobic capacity in asymptomatic bariatric candidates with very severe morbid obesity. Rev Hosp Clin Fac Med Sao Paulo. 2004;59:181-6.

27. Wei YF, Wu HD, Yung-Chieh YPD, Huang CK, Tai CM, Hsuan CF. The impact of metabolic parameters on the change of pulmonary function in obese patients. Surg Obes Relat Dis. 2014;10:23-8.

28. Cirillo DJ, Agrawal Y, Cassano PA. Lipids and pulmonary function in the Third National Health and Nutrition Examination Survey. Am J Epidemiol. 2002;155:842-8.

\section{Submit your next manuscript to BioMed Central and take full advantage of:}

- Convenient online submission

- Thorough peer review

- No space constraints or color figure charges

- Immediate publication on acceptance

- Inclusion in PubMed, CAS, Scopus and Google Scholar

- Research which is freely available for redistribution 